\title{
Distinct trajectories of perinatal depression in Chinese women: application of latent growth mixture modelling
}

\author{
Lan Hong ${ }^{1}$, Tao Le ${ }^{1}$, Yinping Lu' ${ }^{1}$, Xiang Shi ${ }^{1}$, Ludan Xiang ${ }^{1}$, Meng Liu ${ }^{1}$, Wenmiao Zhang ${ }^{2}$, Meixi Zhou ${ }^{2}$, \\ Jiangling Wang ${ }^{2}$, Dongwu $\mathrm{Xu}^{1 *}, \mathrm{Xin} \mathrm{Yu}^{1 *}$ and Ke Zhao ${ }^{1,3^{*}}$
}

\begin{abstract}
Background: Current research on perinatal depression rarely pays attention to the continuity and volatility of depression symptoms over time, which is very important for the early prediction and prognostic evaluation of perinatal depression. This study investigated the trajectories of perinatal depression symptoms and aimed to explore the factors related to these trajectories.
\end{abstract}

Methods: The study recruited 550 women during late pregnancy ( $32 \pm 4$ weeks of gestation) and followed them up 1 and 6 weeks postpartum. Depressive symptoms were measured using the Edinburgh Postnatal Depression Scale (EPDS). Latent growth mixture modelling (LGMM) was used to identify trajectories of depressive symptoms during pregnancy.

Results: Two trajectories of perinatal depressive symptoms were identified: "decreasing" $(n=524,95.3 \%)$ and "increas-

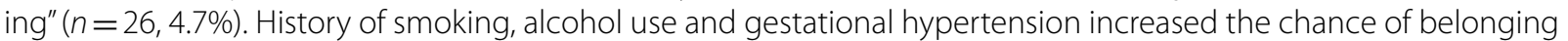
to the increasing trajectories, and a high level of social support was a protective factor for maintaining a decreasing trajectory.

Conclusions: This study identified two trajectories of perinatal depression and the factors associated with each trajectory. Paying attention to these factors and providing necessary psychological support services during pregnancy would effectively reduce the incidence of perinatal depression and improve patient prognosis.

Keywords: Longitudinal trajectories, LGMM, Perinatal depression, Social support

\section{Introduction}

The World Health Organization (WHO) widely defines perinatal depression (PND) as a severe depressive episode during pregnancy or a year after childbirth. The high prevalence of PND is a global phenomenon [1]. In

\footnotetext{
*Correspondence: wzxdw@126.com; yuxin@bjmu.edu.cn; cocozk1986@163. com

${ }^{1}$ School of Mental Health, Wenzhou Medical University, Wenzhou 325035,

China

${ }^{3}$ The Affiliated Kangning Hospital of Wenzhou Medical University,

Wenzhou 325035, China

Full list of author information is available at the end of the article
}

high-income countries, the prevalence of antenatal and postnatal depression varies between 7 and 15\% [2], and between 19 and $25 \%$ in low-income countries [3]. PND is considered one of the most common complications of pregnancy and has a significant impact on the mother, her offspring and even her entire family $[4,5]$. When not treated properly, PND has a negative impact on the outcome of childbirth [6], the child's health, and their social and emotional development [7]. Previous theoretical developments have revealed that children whose mothers suffered from PND have a significantly higher risk of depression compared to children whose mothers did not 
experience PND, and this risk persists from childhood through to adolescence and adulthood. For children of mothers with PND, the probability of being diagnosed with depression in adolescence and adulthood, respectively, is almost 1.28 times and 3.4 times greater than that of children whose mothers did not have PND [8, 9]. Even more seriously, the adverse effects of PND are far-reaching and intricate, lasting for multiple generations; this is referred to as intergenerational transmission $[10,11]$.

Previously, most studies of PND were cross-sectional in nature. The typical strategy used to evaluate the severity of depressive symptoms was to categorise thresholds of severity at a single time point [12]. Some scholars argue that the symptoms of depression are diverse and can differ with respect to onset, course, duration and severity [13-15]. Thus, it is difficult to fully explore the causal factors involved in the onset and variation in depressive symptoms when considering a depressive episode as a point rather than a continuous line and ignoring the continuity and fluctuations in the disorder $[16,17]$. Researchers widely consider that PND can occur from the first trimester to one year after delivery [18]. There are significant differences in the incidence of depression in the different periods of pregnancy. The prevalence of depressive symptoms in the first and second trimesters is much lower than in the third trimester [19]. Due to the long duration of pregnancy, women can experience mood fluctuations throughout the various stages of pregnancy [20]. Some studies have shown that diverse individual characteristics play a significant role in the onset, course, duration and severity of the disease [13-15]. Early surveillance of these fluctuations, and early behavioural intervention and psychological counselling will have a positive impact on the outcomes of perinatal depression. This could also help clinicians to identify at risk groups of women, who may experience adverse outcomes in the future (even in the early stages of pregnancy) [21, 22]. It is essential to understand the occurrence, development and variation in PND throughout the perinatal period and implement interventions as early as possible. Longitudinal mixed effect and growth mixed models are usually used to evaluate the development of perinatal depression symptoms [23]. Variation in the progression or trajectory of symptoms is assessed, and potential subgroups are identified; these can explain the different characteristics of depression symptoms in the different potential groups [24].

Several different PND trajectories have been reported $[22,25]$, but there is considerable heterogeneity in the reports. A meta-analysis of 23 studies related to PND symptom trajectories found that some research teams determined the trajectory of depression based on the characteristics and severity of the disease [26]. In contrast, others chose advanced statistical methods [2730]. Thus, the variation in the number of final trajectories reported in different studies, ranging from two to six different PND trajectories, is likely related to the different grouping standards. Further, the various reported trajectories are inconsistent and sometimes even contradictory. Many predictors attributed to a high symptom level trajectory have been identified, for example, younger age, low education level, unemployment and low-level social support $[26,31]$. Other studies have reported that pregnancy complications increase the possibility of a persistent depression trajectory. The persistent depression trajectory is also associated with the maternal preterm delivery than other trajectories [27]. There is less published evidence for a dynamic trajectory of depression in the Asian population.

The multiple trajectories in the development of depressive symptoms indicate that there may be specific risk factors that lead to particular patterns of symptoms. Exploration of depression trajectories and their predictive factors will assist in the detection of positive cases [32], facilitate timely targeted interventions, and offer individualized treatments. To this end, the current study aimed to provide new evidence on PND dynamic trajectories in the Asian population while also exploring changes in the trajectory of depressive symptoms and evaluating related predictive factors. In particular, the focus was on the influence of factors such as social support on PND trajectories. The following hypotheses were formulated:

(a) Depressive symptoms of pregnant women in the perinatal period have different development trajectories.

(b) Perinatal depression is related to a variety of social and environmental factors.

Validation of these hypotheses will contribute to an improved understanding of perinatal depression and will provide guidance for psychological intervention and support.

\section{Method}

This study was part of a longitudinal research project on the prenatal and postnatal mental health of pregnant and lying-in women at the First Affiliated Hospital of Wenzhou Medical University. The study was conducted from January 2018 to January 2019.

\section{Setting and participants}

The Department of Obstetrics of the First Affiliated Hospital of Wenzhou Medical University participated in the current study. The annual obstetric outpatient 
volume of this hospital exceeds 110,000 . In total, 626 women were randomly selected from the outpatient clinic, of whom 550 met the inclusion criteria for this study. Of these, 63 women were lost in the first followup and 40 were lost in the second follow-up. Analyses in this paper were conducted in 550 women. Detailed information regarding participation at each follow-up is presented in Fig. 1.
A group of professionally trained investigators assisted the participants to complete the self-report survey. The researchers explained the research content to the participants before the participants voluntarily provided written informed consent. The questionnaires were completed anonymously and were numerically coded. Participants were also informed that they could withdraw at any time. After each participant completed

Assessed for eligibility (626)

Inclusion criteria:

1) $18-40$ years old;

2) third trimester $(32 \pm 4$ weeks of gestation);

3 ) voluntarily sign informed consent.

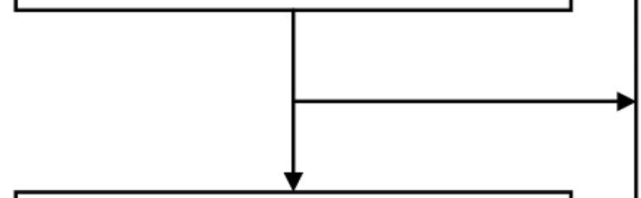

T1: 550 pregnant women included in study 1)complete EPDS scale

2)complete Social Support Rating Scale

3)collect demographic and pregnancy information

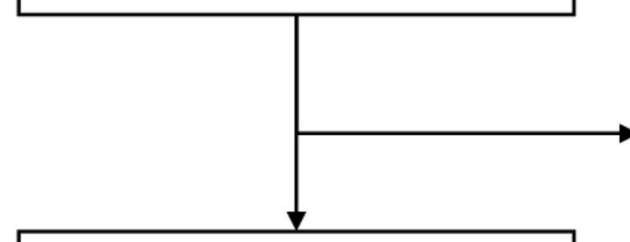

T2: 487 participants included in study
Excluded:

1) family history of mental illness: 17

2) complicated with severe heart disease, infectious disease, severe preeclampsia or eclampsia during pregnancy : 13

3) withdrawal of informed consent, lack of co-operation, or failure to complete the scale: 46

63 participants without complete data

1) 16 of them were withdrawn due to

change the hospital

2) 47 participants refused to continue research due to physical discomfort

40 participants were lost to follow-up after delivery

T3: 447 participants included in study

Fig. 1 Sample flow chart. T1: Third trimester (32 \pm 4 weeks of gestation), T2: 1 week postpartum, T3: 6 weeks postpartum 
the survey, the researchers immediately reviewed their results.

\section{Procedure}

The Edinburgh Postnatal Depression Scales (EPDS) was administered at three time points. The first time point was during the prenatal period, within the third trimester (gestational week $32 \pm 4, \mathrm{~T} 1$ ). The other two time points were during the postnatal period, at 1 week (T2) and 6 weeks postpartum (T3). In addition to the EPDS, participants completed demographic questions and the Social Support Rating Scale (SSRS) at T1. The first follow-up (T2) was conducted on the ward. The second follow-up (T3) was conducted during the participant's outpatient review. Three days before their scheduled outpatient obstetric appointment, the researcher called the participant to confirm the date of their review and to remind them that they would be completing their second follow-up survey at this review appointment.

The inclusion criteria for the study were as follows: 1 ) $18-40$ years old; 2) third trimester ( $32 \pm 4$ weeks of gestation); and 3) voluntarily signed informed consent.

The exclusion criteria were: 1) family history of mental illness; 2) severe heart disease, infectious disease, severe preeclampsia, or eclampsia during pregnancy; and 3) withdrawal of informed consent, lack of co-operation or failure to complete the scale.

\section{Measures}

\section{Self-report demographic survey}

Under the supervision of trained evaluators, the participants filled out the social and demographic section of the survey: age, location (city, rural), years of education ( $\leq 9$ years, 10-12 years, 13-16years), monthly income (low: < $¥ 5000$ ), high: $\geq ¥ 5000$ ), abortion history (Yes, No), behavioural factors (history of smoking, history of alcohol and exercise during pregnancy - (Yes, No)), pregnancy complications (gestational diabetes and pregnancy-induced hypertension - (Yes, No)).

\section{EPDS}

The Chinese equivalent of the EPDS [33] was used to quantitatively assess participants' depression symptoms at enrolment (T1), 1 week after delivery (T2), and 6 weeks after delivery (T3). The scale was developed by Cox et al. [34] and assesses three dimensions, emotional loss, anxiety, and depression. The scale comprises 10 items, each item is scored according to the severity of symptoms ( $0-3$ points), with total possible scores ranging from 0 to 30 points. The higher the score, the more severe the symptoms of depression [35]. This scale has good reliability and validity in mainland China [36]. The
EPDS has complete measurement equivalence between prenatal and postpartum females; it can be used as a prenatal screening test and is a useful tool for depression treatment [37].

\section{SSRS}

The Chinese equivalent of the SSRS, developed by Xiao Shuiyuan in 1994 [38], was used to assess participants' social support status. The SSRS measures three components, objective support, subjective support, and support utilization, and comprises 10 items. Each item is assessed on a Likert scale. The scale has good reliability and validity [39]. The higher the score, the more social support available to the participant.

\section{Statistical analyses}

First, missing values for the covariates were imputed. For age and years of education there were $9(1.6 \%)$ and $12(2.2 \%)$ women with missing values, respectively. They were imputed with the sample. The missing values for SSRS (33 women) were replaced by the mean. Descriptive analysis (means, standard deviations, counts and percentages) was performed to examine the distributions of the variables.

Second, we explored different development trajectories of perinatal depression via latent variable mixed growth model (LGMM). The missing values were processed by full information maximum likelihood procedure (FIML). Given the skewed count-type nature of the EPDS data (see Additional file 1), we specified a Poisson distribution for the outcome variable. To represent non-equidistant time points between the assessments, factor loadings were fixed to 0,1 and 1.5 to represent assessments at baseline, and then one- and six-weeks postpartum. Random intercept variances were allow to vary across classes. This model was estimated from 1 up to 4 latent classes, using 200 random starting values. Selection of number of classes was decided based on the Akaike information criterion (AIC) [40] and Bayesian information criterion (BIC) [41]. The smaller the AIC and BIC values, the better the fit of the model. The bootstrapped likelihood ratio test (BLRT) and Vuong-Lo-Mendell-Rubin test (VLMR) were also considered. A significant likelihood ratio test for $\mathrm{k}$ classes with $p<0.05$ indicates that the specified $\mathrm{k}$-class model is an improvement over a model with $k-1$ classes [42]. The entropy value indicates the accuracy with which the model can classify individuals into their corresponding classes; it ranges from 0 to 1 . Entropy values $\geq 0.8$ indicate that the classification accuracy exceeds $90 \%$ [43]. In cases where fit indices between the two models were relatively similar, entropy values were also taken into account. Finally, the size and theoretical interpretability of the classes were also considered. 
The LGMM model was estimated with Mplus version 8.0 [44]. The Mplus syntax can be found in Additional file 2.

Third, participants were assigned to latent classes based on their highest posterior probability. Simple logistic regression (using only one predictor variable at a time) was used to explore the association between social and environmental factors with the trajectory class membership. The logistic regression model was performed using SPSS version 24.0. Odds ratios (OR) with $95 \%$ confidence intervals are reported, with a significance level set at $5 \%$.

\section{Results}

Overview of the sample

Descriptive statistics for the sample are presented in Table 1 . On average, participants were 28.7 years of age $(\mathrm{SD}=4.1)$. The majority of participants reported finishing college school $(n=359,65.3 \%)$, living in rural $(n=358$,

Table 1 Characteristics of the sample, by class

\begin{tabular}{|c|c|c|c|c|c|c|}
\hline \multirow[t]{2}{*}{ Demographics } & \multicolumn{2}{|c|}{ Total $(n=550)$} & \multicolumn{2}{|c|}{ Decreasing ( $n=524,95.3 \%)$} & \multicolumn{2}{|c|}{ Increasing $(n=26,4.7 \%)$} \\
\hline & $(n, \%)$ & Mean (SD) & n (\%) & Mean (SD) & $\mathrm{n}(\%)$ & Mean (SD) \\
\hline Age & & $28.7(4.1)$ & & $28.7(4.1)$ & & $29.4(4.1)$ \\
\hline \multicolumn{7}{|l|}{ Location } \\
\hline City & $192(34.9)$ & & $183(34.9)$ & & $9(34.6)$ & \\
\hline Rural & $358(65.1)$ & & $341(65.1)$ & & $17(65.4)$ & \\
\hline \multicolumn{7}{|l|}{ Years of education } \\
\hline$\leq 9$ years & $72(13.1)$ & & $68(13.0)$ & & $4(15.4)$ & \\
\hline 10-12years & $119(21.6)$ & & $116(22.1)$ & & $3(11.5)$ & \\
\hline 13-16years & $359(65.3)$ & & $340(64.9)$ & & $19(73.1)$ & \\
\hline \multicolumn{7}{|l|}{ Monthly income } \\
\hline$<¥ 5000$ & $117(21.3)$ & & $109(20.8)$ & & $8(30.8)$ & \\
\hline$\geq ¥ 5000$ & $433(78.7)$ & & $415(79.2)$ & & $18(69.2)$ & \\
\hline \multicolumn{7}{|l|}{ History of smoking } \\
\hline No & $537(97.6)$ & & $514(98.1)$ & & $23(88.5)$ & \\
\hline Yes & $13(2.4)$ & & $10(1.9)$ & & $3(11.5)$ & \\
\hline \multicolumn{7}{|l|}{ History of alcohol } \\
\hline No & $519(95.3)$ & & $497(94.8)$ & & $22(84.6)$ & \\
\hline Yes & $31(4.7)$ & & $27(5.2)$ & & $4(15.4)$ & \\
\hline \multicolumn{7}{|l|}{ Exercise during pregnancy } \\
\hline No & $478(86.9)$ & & $455(86.8)$ & & $23(88.5)$ & \\
\hline Yes & $72(13.1)$ & & $69(13.2)$ & & $3(11.5)$ & \\
\hline \multicolumn{7}{|l|}{ Abortion } \\
\hline No & $326(59.3)$ & & $310(59.2)$ & & $16(61.5)$ & \\
\hline Yes & $224(40.7)$ & & $214(40.8)$ & & $10(38.5)$ & \\
\hline \multicolumn{7}{|l|}{ Gestational diabetes } \\
\hline No & $491(89.3)$ & & $475(90.6)$ & & $16(61.5)$ & \\
\hline Yes & $59(10.7)$ & & $49(9.4)$ & & $10(38.5)$ & \\
\hline \multicolumn{7}{|l|}{ Gestational hypertension } \\
\hline No & $536(97.5)$ & & $512(97.7)$ & & $24(92.3)$ & \\
\hline Yes & $14(2.5)$ & & $12(2.3)$ & & $2(7.7)$ & \\
\hline Social support & & $29.5(3.8)$ & & $29.7(3.8)$ & & $26.7(3.4)$ \\
\hline Objective social support & & $12.4(2.1)$ & & $12.5(2.0)$ & & $11.3(2.5)$ \\
\hline Subjective social support & & $9.4(1.8)$ & & $9.4(1.8)$ & & $8.6(1.2)$ \\
\hline Availability of support & & $7.7(1.8)$ & & $7.8(1.9)$ & & $7.1(1.4)$ \\
\hline EPDS scores (T1) & & $7.6(3.7)$ & & $7.6(3.8)$ & & $7.0(2.1)$ \\
\hline EPDS scores (T2) & & $6.4(3.5)$ & & $6.2(3.3)$ & & $10.5(3.2)$ \\
\hline EPDS scores (T3) & & $6.2(4.5)$ & & $5.4(3.3)$ & & $18.4(4.5)$ \\
\hline
\end{tabular}


Table 2 Fit indices of the for the LGMM models of EPDS, for increasing number of classes (1 to 4)

\begin{tabular}{lllllll}
\hline No. of classes & AIC & BIC & BLRT & VLMR & Entropy & N per class \\
\hline 1 & 7893.001 & 7905.931 & - & - & - & - \\
$\mathbf{2}$ & $\mathbf{7 7 8 0 . 1 5 5}$ & $\mathbf{7 8 1 0 . 3 2 5}$ & $\boldsymbol{p}<. \mathbf{0 0 1}$ & $\boldsymbol{p}<. \mathbf{0 0 1}$ & $\mathbf{. 8 6 2}$ & $\mathbf{5 2 4 / 2 6}$ \\
3 & 7726.320 & 7773.729 & $p<.001$ & $p<.001$ & .563 & $360 / 19 / 171$ \\
4 & 7696.551 & 7761.200 & $p<.05$ & $p<.05$ & .641 & $19 / 357 / 169 / 5$ \\
\hline
\end{tabular}

Bold indicates the selected category

Abbreviations: The values reported in this table are hypothetically derived for illustrative purposes. AIC Akaike information criterion, BIC Bayesian information criterion, BLRT Bootstrap likelihood ratio test, VLMR Vuong-Lo-Mendell-Rubin test

Table 3 Most likely latent class membership (row) by latent class (column)

\begin{tabular}{lll}
\hline Model & Decreasing & Increasing \\
\hline Decreasing & 0.971 & 0.029 \\
Increasing & 0.103 & 0.897 \\
\hline
\end{tabular}

$65.1 \%$ ), and monthly income $\geq ¥ 5000(n=433,78.7 \%)$. Additionally, the mean values of EPDS at the three time points were 7.6 $(\mathrm{SD}=3.7), 6.4(\mathrm{SD}=3.5), 6.2(\mathrm{SD}=4.5)$.

\section{Identification of trajectories}

The fit indices of the models generated through LGMM are reported in Table 2. The four- class solution was excluded given that the solution had one class comprising less than 10 women [27]. The AIC and BIC values suggested that the three-class solution yielded the best fit while the entropy value favoured the two-class solution.
Compared with the two-class solution, the three-class solution produced one new subgroup (31.1\%) characterized by the lowest and consistently declining depressive symptoms. However, the entropy was lower (0.563), indicating a poor latent classification quality. Taking these into consideration, the two-class solution was chosen as the optimal solution. The indices in the diagonal in Table 3 show that the classification accuracy was acceptable, with positive predictive values ranging from 89.7 to 97.1\%.

The (small) increasing class is very homogeneous (close to zero random intercept), as shown in Additional file 3. Thus, all having the same expected trend, while in the other class individuals vary more around their mean trend. The estimated mean EPDS scores of women allocated to the two trajectories are presented in Fig. 2. The decreasing trajectory, with a estimated mean baseline score of 7.09, decreased to 5.64 at one-week postpartum and stabilized at 5.03 at six-weeks postpartum. The increasing group was characterised by no depressive

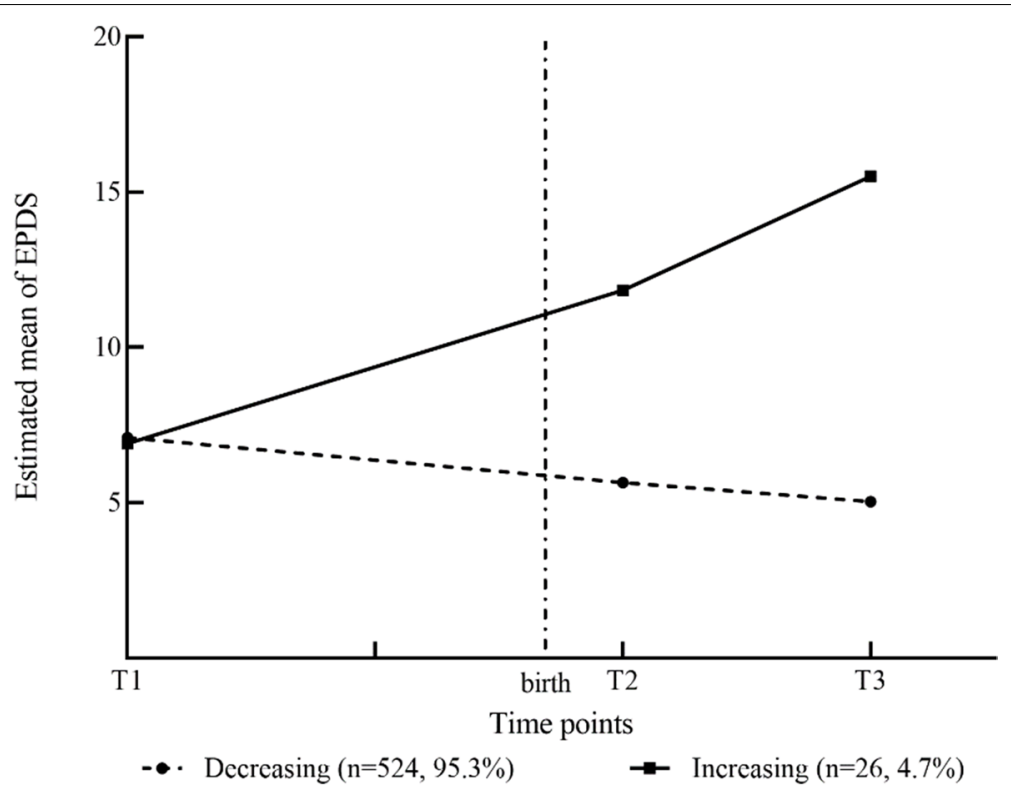

Fig. 2 Estimated means for 2-class solution of EPDS ( $n=550)$. T1: $32 \pm 4$ weeks gestation, T2: 1 week postpartum, T3: 6 weeks postpartum 
symptoms at recruitment (estimated mean $=6.90$ ), but increasing depression scores at one- and six-weeks postpartum (estimated mean $=15.50$ ). The minority of the sample was allocated to class $2(n=26,4.7 \%)$, with $95.3 \%$ of women $(n=524)$ allocated to the decreasing group.

\section{Predictors of trajectories}

The results of the logistic regressions (reported in Table 4) indicated that the level of objective social support was important, greater overall levels of objective social support reduced the chances of worsening depression $(\mathrm{OR}=0.76,95 \% \mathrm{CI}: 0.62-0.95)$. Greater overall levels of subjective social support at baseline decreased the odds of being assigned to the "increasing" group $(\mathrm{OR}=0.81,95 \% \mathrm{CI}$ : 0.67-0.98). Participants with a history of smoking and alcohol use prenatally were 6.7 (95\%CI: $1.73-26.02)$ and 3.35 (95\%CI: 1.08-10.40) times more likely to belong to the "increasing" group. Mothers who reported prenatal gestational hypertension were 5.33 times more likely (95\% CI: $1.07-24.49)$ to belong to the "increasing" group.

\section{Discussion}

Two heterogeneous subgroups predict the development of perinatal depression

LGMM was used to examine the heterogeneity of perinatal depressive symptoms from an individual-centred perspective and subsequently, the subtype characteristics of different prenatal and postnatal trajectories were described. In addition, we specified a Poisson distribution for the outcome variable. When a Poisson distribution was not specified, (thus, assuming normality), different classes emerged and with worse fit indices value, resulting in invalid findings, model misinterpretations, and possible non-intended practical implications [45].

The findings indicated that perinatal depression is heterogeneous and can be categorised based on specific characteristics of the individual. Specifically, the course of perinatal depression can be classified into two heterogeneous sub-groups or cohorts: "decreasing" and "increasing"; that is, two trajectories of PND were identified in this study. The majority of women $(95.3 \%)$ were in a very stable state. They maintained a good mood throughout the perinatal period (EPDS scores were stable at a low level). This means that the majority of women remain at low risk of developing depressive symptoms during the perinatal period. This finding is consistent with previous research results [26-28]. However, the baseline EPDS scores in this study are higher than those observed in more developed countries. This may be related to different economic levels and living conditions between countries. Nonetheless, the severity of PND symptoms may significantly change over time in any population. In this
Table 4 Predictors of the latent trajectory group for perinatal depression symptom based on the logistic regression (reference class: decreasing)

\begin{tabular}{|c|c|c|c|}
\hline \multirow[t]{2}{*}{ Variables } & \multicolumn{3}{|c|}{ Increasing $(n=26,4.7 \%)$} \\
\hline & $O R$ & $95 \% \mathrm{Cl}$ & $p$ \\
\hline Age & 1.05 & $0.95-1.15$ & 0.352 \\
\hline \multicolumn{4}{|l|}{ Location } \\
\hline Rural & 1.01 & $0.44-2.32$ & 0.974 \\
\hline City & ref & & \\
\hline \multicolumn{4}{|l|}{ Educational level } \\
\hline$\leq 9$ years & 1.05 & $0.35-3.19$ & 0.928 \\
\hline 10-12years & 0.46 & $0.13-0.60$ & 0.222 \\
\hline 13-16years & ref & & \\
\hline \multicolumn{4}{|l|}{ Monthly income } \\
\hline$<¥ 5000$ & 1.69 & $0.72-3.40$ & 0.230 \\
\hline$\geq ¥ 5000$ & ref & & \\
\hline \multicolumn{4}{|l|}{ History of smoking } \\
\hline Yes & 6.70 & $1.73-26.02$ & 0.006 \\
\hline No & ref & & \\
\hline \multicolumn{4}{|l|}{ History of alcohol } \\
\hline Yes & 3.35 & $1.08-10.40$ & 0.037 \\
\hline No & ref & & \\
\hline \multicolumn{4}{|l|}{ Exercise during pregnancy } \\
\hline Yes & 0.86 & $0.25-2.94$ & 0.810 \\
\hline No & ref & & \\
\hline \multicolumn{4}{|l|}{ Abortion } \\
\hline Yes & 1.12 & $0.49-2.48$ & 0.810 \\
\hline No & ref & & \\
\hline \multicolumn{4}{|l|}{ Gestational diabetes } \\
\hline Yes & 1.60 & $0.53-4.83$ & 0.402 \\
\hline No & ref & & \\
\hline \multicolumn{4}{|l|}{ Gestational hypertension } \\
\hline Yes & 5.33 & $1.07-24.49$ & 0.041 \\
\hline No & ref & & \\
\hline Social support & 0.84 & $0.77-0.93$ & 0.001 \\
\hline Objective social support & 0.76 & $0.62-0.95$ & 0.015 \\
\hline Subjective social support & 0.81 & $0.67-0.98$ & 0.028 \\
\hline Availability of support & 0.83 & $0.62-1.10$ & 0.183 \\
\hline
\end{tabular}

A simple logistic regression was performed, using only one predictor variable at a time

OR Odds ratio, $\mathrm{Cl}$ Confidence interval

study, 4.7\% of women reported elevated PND symptoms over time, which is in contrast to previous studies [27, 46-48]. For example, a study of 425 pregnant women in South Africa found two depression trajectories [48]. The reason for this difference could be that the study in South Africa focused on low-income women, and a lack of food and living resources might affect the trajectory of perinatal depression. Moreover, some studies have reported the existence of a chronic and persistent high-level 
depression trajectory [27]. In this study, only $37 \%$ of the subjects lived with their partners and nearly $40 \%$ of the subjects were unmarried. In contrast, in the current study, more than $95 \%$ of women were married, and thus, would have more support from their partners, which has a positive effect on depressive symptoms [47]. In contrast, a long-term study conducted in Norway found no increasing trajectory, only a decreasing and lower EPDS trajectory [46]. This may be because women in that study had a higher education level, which may reduce the risk of depressive symptoms.

\section{Demographic characteristics of the two perinatal depression classes}

The findings also suggest that that women with a history of smoking, alcohol use and gestational hypertension were more likely to experience worsening depressive symptoms. Passive smoking during pregnancy can lead to adverse pregnancy outcomes, including preterm birth, low birth weight, congenital disabilities, sudden infant death syndrome, and neurological and respiratory diseases $[49,50]$. Data from the WHO data indicate that the rate of active smoking among Chinese women is low compared to European and American women. The rate of smoking among women aged over 15 years (after age standardization) is $20.7 \%$ in Europe, $12.4 \%$ in the Americas, and $1.9 \%$ in China [51]. Smoking during pregnancy is much less common in low- and middle-income countries, with an overall prevalence of $1.3 \%$ (range $0-15 \%$ ), as estimated from the 2001-2012 Demographic and Health Survey data from 54 countries [52]. In contrast, Chinese women are fundamentally victims of passive smoking [51]. There is evidence that prenatal alcohol exposure at moderate and higher levels increase the odds of child neurobehavioural problems [53], including behaviour, aggression, attention, social functioning [54] and emotional problems [55]. In addition, the adverse effects of high prenatal alcohol exposure are more likely to occur in the offspring of women with a lower socio economic status (SES) than of those with a higher SES $[56,57]$. Overall, the history of high levels of prenatal smoking and alcohol exposure can lead to adverse pregnancy outcomes, thereby increasing women's levels of anxiety and depression. Therefore, pregnant women or women preparing for pregnancy should avoid smoking and drinking behaviors to reduce the effects of alcohol on physical, mental and fetal health.

Equally, pregnancy-induced hypertension has a considerable impact on both the mother and baby, leading to various obstetric and perinatal complications. Approximately $70 \%$ of pregnant women with hypertension during pregnancy develop preeclampsia, which has a worldwide incidence of 2 to $8 \%$, or 2 to $16 \%$ in developing countries
[58]. It is responsible for approximately 63,000 maternal deaths each year and is the principal cause of maternal and newborn deaths [59]. Pregnancy-induced hypertension increases anxiety about the outcome of a pregnancy. Thus, the negative effects of smoking history and pregnancy-induced hypertension in this study are easily understood. Such negative stimulation significantly predicts depression, and the more negative sexual events, the higher the likelihood of depression [60-63].

Predictive effects of social support on perinatal depression As an essential component of external resources, social support has consistently been positively correlated with psychological health $[64,65]$. According to the stressbuffering model, social support may mitigate the psychological impact of a stressful event on mental health by attenuating the stress appraisal response [66]. Women tend to rate the harmful effects of depression and anxiety lower if they perceive more social support, thus reducing the impact of stressful events and leading to less negative emotions [67]. In the current study, the lower the level of subjective and objective social support, the more likely it is that depression will worsen. To date, there have been few studies examining the outcomes of subjective social support. For example, anecdotal evidence suggests that persistent major depression can weaken a patient's subjective social support. When depressive symptoms are alleviated, social support levels will be significantly increased [68], an observation that is consistent with the current results where subjective social support was found to be a protective factor for perinatal depression. Furthermore, we propose that the more subjective support that is available, the more likely it is that a pregnant woman will be emotionally stable both before and after giving birth. Chinese research on subjective social support also shows that individuals with higher levels of subjective social support are more confident, feel more respected, understood and supported, and have fewer emotional disorders $[69,70]$. Recent studies have also shown that a lack of objective support (such as material support, network support, marriage, and family support) for postpartum patients with depressive symptoms is detrimental [71]. This suggests that caring, support and encouragement from family and friends during pregnancy is the best way to relieve low mood and avoid the development of depressive symptoms and episodes.

\section{Intervention implications for perinatal depression}

The U.S. Preventive Services Task Force recommends that women be screened for depression during pregnancy and postpartum care [72]. The current results suggest that women with low social support levels, a history of smoking, alcohol use or gestational hypertension are at 
high risk perinatally. It is essential to provide timely perinatal mental health education for pregnant women, particularly those at high risk. This education process would enable women to understand the occurrence, development and prevention of perinatal depression. Pregnant women, particularly those at high risk of perinatal depression, would be empowered to monitor their emotions, screen for mood swings and depressive symptoms, and seek psychological interventions from professional, medical and health institutions in a timely fashion.

\section{Limitation}

This study's limitations are as follows: 1 ) self-report questionnaire may have an impact on depression; 2) only the high-risk period was investigated: from the third trimester to 6 weeks postpartum: future studies should study the mood of perinatal depression (from pregnancy to 1 year postpartum) entirely, to characterise the trends of perinatal depression over the entire pregnancy; 3 ) the demographic and related characteristics data collected in this study are not comprehensive, and other factors may exist which augment the overall outcomes Future studies should include more variables such as women's personality, and interpersonal relationships can be investigated to explore their specific impact on the development of depression; 4) the covariates only distinguished between belonging to either of the classes, but not how covariates may have impact on the (heterogeneous) EPDS levels within the largest class.

\section{Conclusion}

This study has identified two trajectories of perinatal depression and the factors associated with each trajectory. The results demonstrated that higher social support is a protective factor for perinatal depression, while smoking, alcohol use history and prenatal hypertension during pregnancy are risk factors. As an extension of this research, it may be possible to achieve early identification of women at high risk of perinatal depression. In order to improve the depression symptoms of pregnant women, more attention should be paid to individuals with risk factors. Women with emotional and family/relationship problems should receive more social support. In future studies, these factors can be incorporated into a screening tool to identify women at risk of perinatal depression.

\footnotetext{
Abbreviations

PND: Perinatal depression; WHO: World Health Organization; AIC: Akaike information criteria; BIC: Bayesian information; BLRT: Bootstrap likelihood ratio test; VLMR: Vuong-Lo-Mendell-Rubin test; EPDS: Edinburgh Postnatal Depression Scale; SSRS: Social Support Rating Scale; LGMM: Latent variable mixed growth model; OR: Odds ratio; Cl: Confidence interval.
}

\section{Supplementary Information}

The online version contains supplementary material available at https://doi. org/10.1186/s12884-021-04316-0.

Additional file 1. EPDS distribution histogram (T1: $n=550, T 1: n=487$, T3: $n=447)$.

Additional file 2. Mplus Syntax.

Additional file 3. Parameter estimates of the final two class.

Additional file 4. Demographic information and questionnaires.

\section{Acknowledgements}

We would like to thank Department of Obstetrics, First Affiliated Hospital of Wenzhou Medical University for providing us with the representative dataset. We would also like to extend our thanks to the women who participated in this research.

\section{Authors' contributions}

Authors KZ, DX, XY, WZ, JW and MZ designed the study and wrote the protocol, and revised the paper. Author XS, LX collected information from pregnant women and conducted the statistical analysis. Author $L H, T L, Y L$, $\mathrm{ML}$ conducted literature searches and wrote the first draft. Author KZ, LH, TL reviewed and edited the manuscript. All authors contributed to and have approved the final manuscript.

\section{Funding}

This research was supported by Zhejiang Provincial Natural Science Foundation of China under Grant NO.LQ18H090009, LY19H090015.

\section{Availability of data and materials}

The data used and analyzed during the study are available from the corresponding author if the request is reasonable.

\section{Declarations}

Ethics approval and consent to participate

The study protocol was reviewed and approved by the Research Ethics Committee, Wenzhou Medical University, reference number 2018-KY043 before the research was carried out. In addition, the First Affiliated Hospital of Wenzhou Medical University also reviewed the research proposal after ethical approval had been granted. The research project was then discussed with relevant local authorities in the study district such as the researchers and medical staff of Department of Obstetrics, First Affiliated Hospital of Wenzhou Medical University.

At the beginning of the research, the researchers explain the project to the group of attendees and their spouses / accompanying person. The information included the aims of the study, the methods of data and sample collection, potential advantages and disadvantages of participation, the expected benefits of carrying out the research, principle of privacy and confidentiality, declaration of voluntary participation and contact information of the researcher. Potential participants were also informed that they could withdraw at any time.

The study was performed in accordance with the Declaration of Helsinki and all included participants signed informed consent. To ensure confidentiality interviews were conducted privately and each participant was assigned a unique identity number that was used to anonymise questionnaires, and result record forms.

\section{Consent for publication}

Not applicable for this study.

\section{Competing interests}

The authors have no competing interests to report.

\section{Author details}

${ }^{1}$ School of Mental Health, Wenzhou Medical University, Wenzhou 325035, China. ${ }^{2}$ Department of Obstetrics, First Affiliated Hospital of Wenzhou Medical 
University, Wenzhou, China. ${ }^{3}$ The Affiliated Kangning Hospital of Wenzhou Medical University, Wenzhou 325035, China.

Received: 23 January 2021 Accepted: 3 December 2021 Published online: 10 January 2022

\section{References}

1. Sarah E, Amber S, Alison W, Jayne B, Olanrewaju S, Lorenz W, et al. Modelling of psychosocial and lifestyle predictors of peripartum depressive symptoms associated with distinct risk trajectories: a prospective cohort study. Sci Rep. 2018;8(1):12799.

2. Gelaye B, Rondon MB, Araya R, Williams MA. Epidemiology of maternal depression, risk factors, and child outcomes in low-income and middleincome countries. Lancet Psychiatry. 2016;3(10):973-82.

3. Rahman A, lqbal Z, Harrington R. Life events, social support and depression in childbirth: perspectives from a rural community in the developing world. Psychol Med. 2003;33(7):1161-7.

4. Sun JW, Cao DF, Li JH, Zhang X, Cao FL. Profiles and characteristics of clinical subtypes of perinatal depressive symptoms: a latent class analysis. J Adv Nurs. 2019:75(11):2753-65.

5. Stein A, Pearson RM, Goodman SH, Rapa E, Rahman A, Mccallum M, et al. Effects of perinatal mental disorders on the fetus and child. Lancet. 2014;384(9956):1800-19.

6. Lusskin SI, Pundiak TM, Habib SM. Perinatal depression: hiding in plain sight. Can J Psychiatry. 2007;52(8):479-88.

7. Hayes B, Sharif F. Behavioural and emotional outcome of very low birth weight infants - literature review. J Matern Fetal Neonatal Med. 2009;22(10):849-56.

8. Pearson RM, Evans J, Kounali D, Lewis G, Heron J, Ramchandani PG, et al. Maternal depression during pregnancy and the postnatal period: risks and possible mechanisms for offspring depression at age 18 years. JAMA Psychiatry. 2013;70(12):1312-9.

9. Plant DT, Pariante CM, Sharp D, Pawlby S. Maternal depression during pregnancy and offspring depression in adulthood: role of child maltreatment. Br J Psychiatry. 2015;207(3):213-20.

10. Bowers ME, Yehuda R. Intergenerational transmission of stress in humans. Neuropsychopharmacology. 2015;41(1):232-44.

11. Grundwald JN, Brunton JP. Prenatal stress programs neuroendocrine stress responses and affective behaviors in second generation rats in a sex-dependent manner. Psychoneuroendocrinology. 2015;62:204-16.

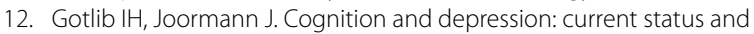
future directions. Annu Rev Clin Psychol. 2010;6(1):285-312.

13. Ahmed A, Bowen A, Feng CX, Muhajarine N. Trajectories of maternal depressive and anxiety symptoms from pregnancy to five years postpartum and their prenatal predictors. BMC Pregnancy Childbirth. 2019;19(1):26.

14. Campbell SB, Matestic P, Stauffenberg CV, Mohan R, Kirchner T. Trajectories of maternal depressive symptoms, maternal sensitivity, and children's functioning at school entry. Dev Psychol. 2007;43(5):1202-15.

15. Chang JJ, Halpern CT, Kaufman JS. Maternal depressive symptoms, father's involvement, and the trajectories of child problem behaviors in a US national sample. Arch Pediatr Adolesc Med. 2007;161(7):697-703.

16. Banti S, Mauri M, Oppo A, Borri C, Rambelli C, Ramacciotti D, et al. From the third month of pregnancy to 1 year postpartum. Prevalence, incidence, recurrence, and new onset of depression. Results from the perinatal depression-research \& screening unit study. Compr Psychiatry. 2011;52(4):343-51.

17. Martini J, Petzoldt J, Einsle F, Beesdo-Baum K, Höfler M, Wittchen HU. Risk factors and course patterns of anxiety and depressive disorders during pregnancy and after delivery: a prospective-longitudinal study. J Affect Disord. 2015;175:385-95.

18. Littlewood E, Ali S, Ansell P, Dyson L, Gascoyne S, Hewitt C, et al. Identification of depression in women during pregnancy and the early postnatal period using the Whooley questions and the Edinburgh Postnatal Depression Scale: protocol for the Born and Bred in Yorkshire: PeriNatal Depression Diagnostic Accuracy (BaBY PaNDA) study. BMJ Open. 2016;6(6):e011223.

19. Ferreira CR, Orsini MC, Vieira CR, et al. Prevalence of anxiety symptoms and depression in the third gestational trimester. Arch Gynecol Obstet. 2015;291(5):999-1003.
20. McCall-Hosenfeld JS, Phiri K, Schaefer E, Zhu J, Kjerulff K. Trajectories of depressive symptoms throughout the peri- and postpartum period: results from the first baby study. J Women's Health (Larchmt). 2016;25(11):1112-21.

21. Dennis $\mathrm{CL}$, Hodnett ED. Psychosocial and psychological interventions for treating postpartum depression. Cochrane Database Syst Rev. 2007;4(4):CD006116.

22. Putnam KT, Wilcox M, Robertson-Blackmore E, Sharkey K, Bergink V, Munk-Olsen T, et al. Clinical phenotypes of perinatal depression and time of symptom onset: analysis of data from an international consortium. Lancet Psychiatry. 2017;4(6):477-85.

23. Abarda A, Dakkon M, Azhari M, Zaaloul A, Khabouze M. Latent transition analysis (LTA): a method for identifying differences in longitudinal change among unobserved groups. Procedia Comput Sci. 2020;170:1116-21.

24. Baron E, Bass J, Murray SM, Schneider M, Lund C. A systematic review of growth curve mixture modelling literature investigating trajectories of perinatal depressive symptoms and associated risk factors. J Affect Disord. 2017;223:194-208.

25. Altemus M, Neeb CC, Davis A, Occhiogrosso M, Bleiberg KL. Phenotypic differences between pregnancy-onset and postpartum-onset major depressive disorder. J Clin Psychiatry. 2012;73(12):e1485.

26. Wikman A, Axfors C, Iliadis SI, Cox J, Skalkidou A. Characteristics of women with different perinatal depression trajectories. J Neurosci Res. 2019;98(34):24390.

27. Dekel S, Ein-Dor T, Ruohomäki A, Lampi J, Voutilainen S, Tuomainen TP, et al. The dynamic course of peripartum depression across pregnancy and childbirth. J Psychiatr Res. 2019;113:72-8.

28. Garman EC, Cois A, Tomlinson M, Rotheram-Borus MJ, Lund C. Course of perinatal depressive symptoms among south African women: associations with child outcomes at 18 and 36 months. Soc Psychiatry Psychiatr Epidemiol. 2019;54(9):1111-23.

29. Santo H, Tan X, Salomon R. Heterogeneity in perinatal depression: how far have we come? A systematic review. Arch Womens Ment Health. 2016;20(1):11-23.

30. Christensen AL, Stuart EA, Perry DF, Le HN. Unintended pregnancy and perinatal depression trajectories in low-income, high-risk Hispanic immigrants. Prev Sci. 2011;12(3):289-99.

31. Sarkar NDP, Bardaji A, Peeters Grietens K, Bunders-Aelen J, Baingana F. The social nature of perceived illness representations of perinatal depression in rural Uganda. Int J Environ Res Public Health. 2018;15(6):1197.

32. Meijer J, Beijers C, Van Pampus M, Verbeek T, Stolk R, Milgrom J, et al. Predictive accuracy of Edinburgh postnatal depression scale assessment during pregnancy for the risk of developing postpartum depressive symptoms: a prospective cohort study. BJOG. 2015;121(13):1604-10.

33. Lee DTS, Yip SK, Chiu HFK, Leung TYS, Chung TKH. Detecting postnatal depression in Chinese women - validation of the Chinese version of the Edinburgh postnatal depression scale. Br J Psychiatry. 1998;172(5):433-7.

34. Cox JL, Holden JM, Sagovsky R. Detection of postnatal depression. Development of the 10-item Edinburgh postnatal depression scale. $\mathrm{Br}$ J Psychiatry. 1987;150:782-6.

35. Tang W, Bao C, Xu L, Zhu J, He J. Depressive symptoms in late pregnancy disrupt attentional processing of negative-positive emotion: an eyemovement study. Front Psychiatry. 2019;10:780.

36. Mellgren K, Skogby M, Friberg LG, Tengborn L, Wadenvik H. Sleepdisordered breathing: a risk factor for adverse pregnancy outcomes? Am J Perinatol. 2012;29(04):277-82.

37. Zhao Y, Kane I, Wang J, Shen B, Luo J, Shi S. Combined use of the postpartum depression screening scale (PDSS) and Edinburgh postnatal depression scale (EPDS) to identify antenatal depression among Chinese pregnant women with obstetric complications. Psychiatry Res. 2015;226(1):113-9.

38. Xiao SY. Theoretical foundation and research application about the social support rating scale. J Clin Psychiatry. 1994;4(2):98-100.

39. Xu J, Ou L. Resilience and quality of life among Wenchuan earthquake survivors: the mediating role of social support. Public Health. 2014;128(5):430-7.

40. Akaike H. Information measures and model selection. Int Stat Inst. 1983;50(1):277-90.

41. Raftery AE. Bayesian model selection in social research (with discussion). Sociol Methodol. 1995;25:111-95.

42. Muthén B, Brown CH, Masyn K, Jo B, Khoo ST, Yang CC, et al. Trajectories of perinatal depressive symptoms from early pregnancy to six weeks 
postpartum and their risk factors - a longitudinal study. J Affect Disord. 2002;3(4):459-75

43. Lubke GH, Muthén BO. Performance of factor mixture models as a function of model size, covariate effects, and class-specific parameters. Struct Equ Modeling. 2007;14(1):26-47.

44. Muthén LK, Muthén BO. Mplus user's guide. 8th ed. Los Angeles: Muthén \& Muthén; 1998-2017.

45. Shiyko MP, LiY, Rindskopf D. Poisson growth mixture modeling of intensive longitudinal data: an application to smoking cessation behavior. Struct Equ Modeling. 2012;19(1):65-85.

46. Drozd F, Haga SM, Valla L, Slinning K. Latent trajectory classes of postpartum depressive symptoms: a regional population-based longitudinal study. J Affect Disord. 2018;241:29-36.

47. Woolhouse H, James J, Gartland D, McDonald E, Brown SJ. Maternal depressive symptoms at three months postpartum and breastfeeding rates at six months postpartum: implications for primary care in a prospective cohort study of primiparous women in Australia. Women Birth. 2016;29(4):381-7.

48. Garman EC, Schneider M, Lund C. Perinatal depressive symptoms among low-income south African women at risk of depression: trajectories and predictors. BMC Pregnancy Childbirth. 2019;19(1):202.

49. Collaco JM, Wilson KM, Mcgrath-Morrow SA. More evidence linking smoke-free legislation and lower risk of prematurity and low birth weight. Pediatrics. 2017;139(6):e20170795.

50. Wagijo MA, Sheikh A, Duijts L, Been JV. Reducing tobacco smoking and smoke exposure to prevent preterm birth and its complications. Paediatr Respir Rev. 2015;22:3-10.

51. WHO: WHO global report on trends in prevalence of tobacco smoking 2015. 2015

52. Caleyachetty R, Tait CA, Kengne AP, Corvalan C, Uauy R, Echouffo-Tcheugui JB. Tobacco use in pregnant women: analysis of data from demographic and health surveys from 54 low-income and middle-income countries. Lancet Glob Health. 2014;2(9):e513-20.

53. O'Leary CM, Nassar N, Zubrick SR, Kurinczuk JJ, Stanley F, Bower C. Evidence of a complex association between dose, pattern and timing of prenatal alcohol exposure and child behaviour problems. Addiction. 2010;105(1):74-86.

54. Jacobson JL, Jacobson SW. Drinking moderately and pregnancy: effects on child development. Alcohol Res Health. 1999;23(1):25-30.

55. RoebuckTM, Mattson SN, Riley EP. Behavioral and psychosocial profiles of alcohol-exposed children. Alcohol Clin Exp Res. 1999;23(6):1070-6.

56. Patra J, Bakker R, Irving H, Jaddoe V, Malini S, Rehm J. Dose-response relationship between alcohol consumption before and during pregnancy and the risks of low birthweight, preterm birth and small for gestational age (SGA)-a systematic review and meta-analyses. BJOG. 2011;118(12):1411-21.

57. Pfinder M, Kunst AE, Feldmann R, Van Eijsden M, Vrijkotte TG. Preterm birth and small for gestational age in relation to alcohol consumption during pregnancy: stronger associations among vulnerable women? Results from two large Western-European studies. BMC Pregnancy Childbirth. 2013:13:49.

58. Pregnancy NHBPEPWGoHBPi. Report of the national high blood pressure education program working group on high blood pressure in pregnancy. Am J Obstet Gynecol. 2000;183(1):s1-s22.

59. Khan KS, Wojdyla D, Say L, Gülmezoglu AM, Look PFV. WHO analysis of causes of maternal death a systematic review. Lancet. 2006;367(9516):1066-74.

60. Chen J, Li X, Mcgue M. Interacting effect of BDNF Val66Met polymorphism and stressful life events on adolescent depression. Genes Brain Behav. 2012;11(8):958-65.

61. Hetolang LT, Amone-P'Olak K. The associations between stressful life events and depression among students in a university in Botswana. S Afr J Psychol. 2017;48(2):255-67.

62. Masahiro S, Ryuji F, Chisato K, Yoshitaka K, Takashi O, Makoto U. Stressful events and coping strategies associated with symptoms of depression: a Japanese general population survey. J Affect Disord. 2019:238:482-8.

63. Van Amelsvoort T, Stikkelbroek Y, Bodden DHM, Kleinjan M, Reijnders M, van Baar AL. Adolescent depression and negative life events, the mediating role of cognitive emotion regulation. PLoS One. 2016;1 1(8):e0161062.

64. Cohen S, Wills TA. Stress, social support, and the buffering hypothesis, Psychol Bull. 1985;98(2):310-57.
65. Schradle SB, Dougher MJ. Social support as a mediator of stress: theoretical and empirical issues. Clin Psychol Rev. 1985;5(6):641-61.

66. Cohen S. Psychosocial models of the role of social support in the etiology of physical disease. Health Psychol. 1988;7(3):269-97.

67. Park J, Kitayama S, Karasawa M, Curhan K, Markus HR, Kawakami N, et al. Clarifying the links between social support and health: culture, stress, and neuroticism matter. J Health Psychol. 2013;18(2):226-35.

68. Leskelä U, Melartin T, Rytsälä H, Sokero P, Lestelä-Mielonen P, Isometsä E. The influence of major depressive disorder on objective and subjective social support: a prospective study. J Nerv Ment Dis. 2008;196(12):876-83.

69. Xie RH, He G, Walker M, Wen SW. Prenatal social support, postnatal social support, and postpartum depression. Ann Epidemiol. 2009;19(9):637-43.

70. Gan Y, Xiong R, Song J, Xiong X, Chen D. The effect of perceived social support during early pregnancy on depressive symptoms at 6 weeks postpartum: a prospective study. BMC Psychiatry. 2019;19(1):232.

71. O'Neill P, Cycon A, Friedman L. Seeking social support and postpartum depression: a pilot retrospective study of perceived changes. Midwifery. 2019:71:56-62

72. Siu AL, Force USPST, Bibbins-Domingo K, Grossman DC, Baumann LC, Davidson KW, et al. Screening for depression in adults: US preventive services task Force recommendation statement. JAMA. 2016;315(4):380-7.

\section{Publisher's Note}

Springer Nature remains neutral with regard to jurisdictional claims in published maps and institutional affiliations.
Ready to submit your research? Choose BMC and benefit from:

- fast, convenient online submission

- thorough peer review by experienced researchers in your field

- rapid publication on acceptance

- support for research data, including large and complex data types

- gold Open Access which fosters wider collaboration and increased citations

- maximum visibility for your research: over $100 \mathrm{M}$ website views per year

At BMC, research is always in progress.

Learn more biomedcentral.com/submissions 